\title{
What are we missing when we measure accessibility? Comparing calculated and self-reported accounts
}

\author{
Jean Ryan*a,b,c , Rafael H. M. Pereira ${ }^{\mathrm{d}}$ \\ aDepartment of Technology and Society, Lund University, P.O. Box 118, 22100 Lund, Sweden \\ ${ }^{\mathrm{b}}$ K2 The Swedish Knowledge Centre for Public Transport, Bruksgatan 8, 22237 Lund, Sweden \\ ${ }^{\mathrm{c}}$ CASE, Centre for Ageing and Supportive Environments, Lund University, P.O. Box 157, 22100 Lund, \\ Sweden \\ ${ }^{\mathrm{d} I p e a}$ Institute for Applied Economic Research, Brasilia, Brazil
}

\begin{abstract}
Accessibility is increasingly recognised as a key purpose of transport policies. Most of the common practices found both in academic studies and policy planning draw on relatively simple accessibility measures taken as 'objective' indicators that only focus on the interaction between land use and transport. Relatively little attention has been paid to heterogeneity in individual characteristics and in self-reported perceptions of accessibility ('subjective' indicators), and the corresponding differences with respect to available modal options. This study includes a comparison of (1) 'objective' indicators of accessibility to key activities by various modes of transport; and (2) individuals' own perceptions of their capability to access valuable out-of-home activities and the modal options available to them. This study examines the key differences between the two representations of accessibility. The calculated measure was developed using door-to-door travel times to supermarkets and healthcare centres using OpenTripPlanner. The self-reported measure was based on a dedicated capability-oriented travel survey of people aged 65-79 in Sweden's large metropolitan regions: Stockholm, Gothenburg and Malmö. The data were analysed using descriptive statistics and binary and multinomial logistic regressions. The results of this study allow us to gain a greater insight into the ways in which the two accounts differ and can complement one another. We find that conventional transport methods, by overlooking the heterogeneity in people's perceptions of their accessibility, tend to overestimate accessibility levels and underestimate accessibility inequalities. This study shows how perceived accounts of accessibility can be incorporated into conventional accessibility models and improve accessibility analyses.
\end{abstract}

\section{Keywords:}

Accessibility; Mobility; Older people; Capability Approach; Self-reported; Calculated accessibility; Subjective 


\title{
What are we missing when we measure accessibility? Comparing calculated and self-reported accounts
}

\begin{abstract}
Accessibility is increasingly recognised as a key purpose of transport policies. Most of the common practices found both in academic studies and policy planning draw on relatively simple accessibility measures taken as 'objective' indicators that only focus on the interaction between land use and transport. Relatively little attention has been paid to heterogeneity in individual characteristics and in self-reported perceptions of accessibility ('subjective' indicators), and the corresponding differences with respect to available modal options. This study includes a comparison of (1) 'objective' indicators of accessibility to key activities by various modes of transport; and (2) individuals' own perceptions of their capability to access valuable out-of-home activities and the modal options available to them. This study examines the key differences between the two representations of accessibility. The calculated measure was developed using door-to-door travel times to supermarkets and healthcare centres using OpenTripPlanner. The self-reported measure was based on a dedicated capability-oriented travel survey of people aged 65-79 in Sweden's large metropolitan regions: Stockholm, Gothenburg and Malmö. The data were analysed using descriptive statistics and binary and multinomial logistic regressions. The results of this study allow us to gain a greater insight into the ways in which the two accounts differ and can complement one another. We find that conventional transport methods, by overlooking the heterogeneity in people's perceptions of their accessibility, tend to overestimate accessibility levels and underestimate accessibility inequalities. This study shows how perceived accounts of accessibility can be incorporated into conventional accessibility models and improve accessibility analyses.
\end{abstract}

\section{Keywords:}

Accessibility; Mobility; Older people; Capability Approach; Self-reported; Calculated accessibility; Subjective

\section{Introduction}

Having the possibility to participate in out-of-home activities is central for well-being during later life (Mollenkopf et al., 2005; Nordbakke, 2013; Spinney et al., 2009; Ziegler and Schwanen, 2011). Strong associations have been found between the potential for mobility and autonomy, particularly during the ageing process (Mollenkopf et al. 2005). Older people are particularly susceptible to lower levels of accessibility in the transport and land use system (see Mercado et al., 2010; Murray, 2014). The ageing process often results in situations where different modes of transport are not - or are no longer - options for older people (J. Ryan et al., 2016; Siren and Haustein, 2015), in turn resulting in reduced accessibility to everyday out-of-home activities.

During the last two decades we have seen greater momentum in the shift in focus from the concept of mobility to the concept of accessibility (Geurs and Östh, 2016; Handy, 2020; Shen et al., 2012; Silva et al., 2017). This shift has mainly occurred within research, but also to a lesser extent within policy and practice (van Wee, 2016). However, there is still no widespread agreement for how accessibility should be defined or measured (Geurs and Östh, 2016; Miller, 2018; Páez et al., 2012). Most of the common practices and traditional analyses found both in academic studies and policy planning focus mainly on relatively simple accessibility measures that only account for the interaction between land use and transport and somewhat neglect the heterogeneity of the population traversing these systems. Transport accessibility studies are generally based on averages across populations and many assumptions regarding decision-making and routing (Miller, 2018), which are often decoupled from the transport experiences of older people. Furthermore, calculated levels of accessibility using data on land use and the transport system are often referred to as 'objective', even though they require the imposition of the researcher's values and assumptions which may not necessarily reflect the reality experienced by individuals, nor the differences in said reality (Haugen, 2011; Schwanen, 2008). Relatively little attention has been paid to the heterogeneity in individual characteristics; perceptions of accessibility; and the corresponding differences with respect to available modal options. This is particularly important, 
as individuals' transport and mobility decisions are largely influenced by their perceptions of local transport systems and the accessibility they confer. Furthermore, there has been very little discussion about how self-reported/perceived opportunities compare to calculated accessibility (with the exceptions of e.g. Curl et al. (2015); Laatikainen et al. (2015); Lättman et al. (2018); Ryan et al. (2016)). This implies that there is likely to be a discrepancy between what the analyst deems 'accessible' for people and what people themselves perceive to be the case.

At the same time, it is somewhat problematic to empirically assess the distribution of accessibility across a range of individuals based solely on self-reported (often termed 'subjective') accounts. This is because people's accounts can be directly linked to dependence paths, individual preferences and self-selection processes (Bohte et al., 2009; Miller, 2018; Mollenkopf et al., 2011; Schmöcker et al., 2008), all of which are particularly relevant for older people. More in-depth, largely qualitative studies focusing on individuals and their pre-conditions and characteristics provide us with a rich account of these specific individuals' everyday constraints. However, they do not allow us to identify systematic trends, processes or distribution factors in larger population groups. As such, a comparison or combination of the two kinds of accounts (calculated/'objective' and self-reported/'subjective') could provide us with a more accurate picture of accessibility.

For this paper, we draw on a comparison between calculated and self-reported accounts and explore how both perspectives can be brought together in order to give a more comprehensive and perhaps more accurate representation of accessibility. The self-reported elements are drawn from a travel survey conducted with 1149 people aged 65-79 and living in Sweden's large metropolitan regions (LMR) of Stockholm, Gothenburg and Malmö. The survey was specifically designed to capture capabilities related to accessibility and mobility, drawing on individuals' self-reported capability to access valuable out-ofhome activities using different transport modes. Combined with recent developments in transport modelling, these data give us a unique opportunity to draw on both the calculated and the self-reported accounts of accessibility to uncover what may be missing when we focus only on the former. This study advances previous research by exploring how self-reported accessibility accounts can be used to inform so-called objective measures of accessibility commonly used to assess the performance of transportation systems. We draw on the Capability Approach (CA) to illustrate inter-personal differences in capabilities with respect to accessibility. This is with the aim of giving a more comprehensive and accurate representation of accessibility.

\section{Literature overview}

Accessibility has become a central concept in transport policies, with the improvement of accessibility now featuring as a key aim of transport authorities in different parts of the world (Boisjoly and ElGeneidy, 2017; Silva et al., 2017; van Wee, 2016). In Sweden, accessibility for all is defined as a key goal of the transport system at a national level (The Swedish Government, 2009), with accessibility for groups such as older people and people with disabilities a core part of this goal. 'Accessibility planning' is becoming a key concept in Sweden (Gil Solá et al., 2018).

Despite the increasing centrality of accessibility as a concept, definitions are both wide-ranging and numerous. There are, however, three key features pervading most definitions: (1) the 'potential' to reach opportunities (e.g. Hansen 1959; Paez et al. 2012: 141); (2) the 'ease' with which said potential can be realised (e.g. Lättman et al. 2018; Social Exclusion Unit (UK) 2003); and (3) the 'extent' to which opportunities can be reached (e.g. Department for Transport (UK), 2014: 2; Geurs and Ritsema Van Eck 2001).

Corresponding to the large number of definitions is a wide range of metrics available to measure and assess accessibility (Bocarejo S. and Oviedo H., 2012; Geurs and Östh, 2016). The most common approach is place-based accessibility (Dijst et al., 2002; Páez et al., 2012). Metrics in this category reflect accessibility levels as characteristics of locations and include, for example, gravity and cumulative opportunity measures. These metrics capture accessibility solely as a function of the interaction between land use and transport systems. The popularity of such approaches is largely due to their simplicity (Miller, 2018). 
What is somewhat missing from such approaches is an explicit account of how a person's characteristics interfere with her ability to engage with the spatial and transport components (cf. Geurs and Östh, 2016; Geurs and van Wee, 2004). 'Real' accessibility can vary dramatically with individual characteristics such as age, gender, income or physical and cognitive functioning. Moreover, accessibility differs with respect to the type of activity; modal options; time of day; and the respective time constraints of the individual(s) involved (Miller, 2018). Yet the academic and policy literatures predominantly analyse accessibility using place-based metrics that tend to neglect the human component of transport accessibility.

A second approach found in the literature adopts person-based accessibility measures (Dijst et al., 2002; Páez et al., 2012). Accessibility metrics in this approach consider how transport and location characteristics interact with personal characteristics such as age, gender and physical capacity to influence the accessibility levels of a person. Far fewer adopt this approach, in part as a result of the data and computational challenges involved. This category includes, for example, logsum and spacetime accessibility measures that can consider for example the activity schedules, prisms and potential path areas of individuals, drawn from coupling, capacity and authority constraints and resources (Hägerstrand, 1989). For further discussion and application see e.g. Chen and Kwan (2012); Mahmoudi et al. (2019); Patterson and Farber (2015). Still, most of these studies focus purely on transport and land use, and tend to overlook whether and how their calculated accessibility measures differ from subjective accounts of accessibility.

Even what are often referred to as 'objective' measures of accessibility are embedded with assumptions and arbitrary choices that might reflect biases from researchers (Haugen, 2011; Schwanen, 2008). Some have also questioned the normative prescriptions of travel time thresholds in accessibility analyses (how far people 'ought' to travel) (Páez et al., 2012). These are somewhat arbitrary travel times or distances which are considered by the analyst as 'reasonable' in their respective contexts. These have then been contrasted to positive accessibility measures, which are based on the distances which people actually travel (derived from travel survey data and similar sources). When studying the accessibility of older people, such nuanced approaches are even more important given the differences between the distances, travel times, speeds and travel habits for older people compared to the general population.

Although 'objective' or calculated accessibility is by far the most common measure of accessibility, some measures of perceived accessibility do exist. The Perceived Accessibility Scale (referred to as 'PAC') has been developed (Lättman et al., 2016). The PAC includes four statements related to the individual's perceived possibility to use different modes of transport and the perceived possibility to reach preferred activities by said mode of transport. Respondents are asked to provide information regarding their agreement with these statements. The PAC was applied as part of a survey regarding accessibility in the city of Malmö, with results then compared to those of the objective index of travel times and travel time ratios by various modes of transport, finding no clear links between the two (Lättman et al., 2018). Researchers in Finland conducted a participatory GIS-based analysis aiming to capture and combine both objective and subjective measures of accessibility (Laatikainen et al., 2015). Respondents used an online interface to mark out the geolocations of aquatic environments they use, the activities they conduct at these locations, the mode of transport they use to access these locations as well as the frequency with which they access them. They also marked out places they perceive as inaccessible and places that are particularly valuable. Here, it was found that the objective and subjective aspects complemented one another, providing a more detailed account of accessibility, yet produced contradictory results. The authors warn that a focus on the closest available service as part of equity analyses may return unfounded interpretations, with many previous studies disregarding individual preferences and socio-psychological factors that may determine actual usage (ibid.). Curl et al. (2015) compare differences between a GIS-based measure of travel times and self-reported travel times, finding discrepancies between the former and the latter. They highlight that such discrepancies can exist due to differences between the objective measure and reality, between the self-reported values and reality, or indeed a combination of the two. Finally, Ryan et al. (2016) compare perceived and calculated accessibility using a case study of a train station in Perth. They found that calculated levels of accessibility were lower than perceived, and found that results differed by age group. 
Several have argued that the single strongest feature of accessibility is how the spatio-temporal conditions of the transport and land use system are differently perceived and used by individuals (e.g. Páez et al., 2012). Adding weight to this argument, van Wee (2016) emphasises that one of the most relevant, yet taxing, questions facing accessibility research is the extent to which calculated accessibility matches the perceptions of people, and the factors that can be explored to explain any mismatches. Moreover, Haugen (2011) questions the way in which the individual component of accessibility is often framed by normative and general terms, drawing on so-called 'objective' measurements. She concludes that different 'accessibilities' mean different things to different people.

\section{Conceptual Framework}

The proposition that transportation studies would benefit from a more nuanced understanding of accessibility as a capability has been put forward by several researchers (Tyler 2006; Pereira et al., 2017; van Wee, 2012). Researchers like Tyler (2006) and Pereira et al. (2017) claim that a capability framework brings out a more fine-grained understanding of accessibility that acknowledges the diversity of people's needs and constraints when they make their transport decisions, underscoring the importance of the individual component of accessibility. According to these authors, the accessibility levels of individuals can be framed as 'combined capabilities', derived from their respective resources and characteristics as well as their social and environmental contexts. The combined capability of accessibility comprises, for instance, the capabilities to negotiate the public transport system; to leave the home; to walk at a certain speed; and to navigate the city.

Only a few studies have operationalised and advanced the application of capabilities within transport (e.g. Hickman et al., 2017; Nordbakke, 2013; Ryan et al., 2019, 2015; Vecchio, 2020; Wismadi et al., 2014). The CA framework is becoming a point of interest in transport research (Beyazit, 2011; Nordbakke and Schwanen, 2014; Pereira et al., 2017; Ryan et al., 2019). However, to the best of our knowledge, no one has so far challenged accessibility analyses based on either exclusively self-reported or calculated accounts, nor has anyone attempted to combine both self-reported and calculated aspects of accessibility as a capability.

Sen (1995:52-53) stipulates that the data used in the application of the CA should be based on objective accounts. However, he also acknowledges that there are difficulties in the empirical application of the $\mathrm{CA}$, especially given the highly individual-focused nature of the conceptual framework (cf. discussions of Sen's work in Alkire (2008)). For instance, in the case of the analysis of accessibility, what is perceived as 'accessible' by the individual can be shaped by self-selection and path dependence processes, as well as the mobility opportunities and activities that are actually valued by the individual (Mollenkopf et al., 2011). As perception differs among individuals, attempts to compare one individual's situation with another's are hindered. However, Sen also emphasises that it is the individual's prerogative to define what is important for herself (Comim, 2008: 170-173; Deneulin, 2008: 118-119).

The phenomenon of adaptive preference has featured quite heavily as part of the discussion surrounding the CA (e.g. Nussbaum, 2001). Adaptive preference describes the process whereby a person might adjust her preferences/ambitions in order to conform with what she considers social/cultural norms define as normal or acceptable for someone like her (cf. Nussbaum (2001)). For instance, people may experience difficulties but may have adjusted their expectations and preferences according to their restricted circumstances and thus report having sufficient capabilities despite having quite a restricted life compared to others. This could, for instance, mean that an individual reports being able to carry out all necessary daily activities, and having sufficient accessibility levels to do so, even though their accessibility levels are much lower than others reporting the same level of satisfaction with their capabilities. The adaptive preference issue can, however, present itself in virtually all self-reported data. In this case, it is difficult to compare these persons' circumstances with those who are 'better off' by using only self-reported data. This produces additional challenges for accessibility analysis based solely on self-reported accounts, but this issue has been generally overlooked in the transport literature.

For the self-reported element of this study, efforts were made to alleviate some adaptive preference effects by adopting a two-way communication process between the interviewer and respondent. This meant that the interviewer could probe for further information during the course of the interview, posing 
several open-ended questions at different stages of the interview (see Comim 2008: 171 for a further discussion).

This study employs the CA as a framework for analysing accessibility. For this study, accessibility is framed as a combined capability, with the individual's perception of their capability influencing the way in which they can employ it. Heterogeneity in resources and characteristics are considered to affect the capability itself while the individual's perception of their capability is said to affect whether or not and the ways in which - it can be operationalised.

\section{Material and methods}

In this paper we estimated accessibility using two different approaches. This combined capability was measured using calculated estimates of accessibility from the home to key activities at different times of the day using different modes of transport. Self-reported capabilities with respect to accessibility (in relation to specific modes of transport) were used as inputs into these calculated estimates. This was in order to give a more nuanced and accurate representation of accessibility as a combined capability. See Figure 1 for an illustration. 
Heterogeneous resources

and characteristics

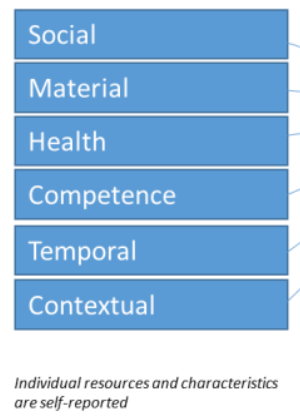

are self-reported
Accessibility levels

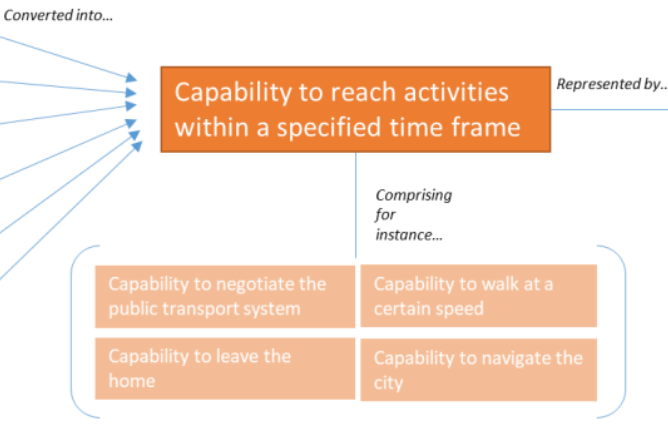

Measurement of

accessibility levels

Calculated measure of

accessibility from the

home to key activities

Self-reported modal

options

Fig. 1A Application for the current analysis

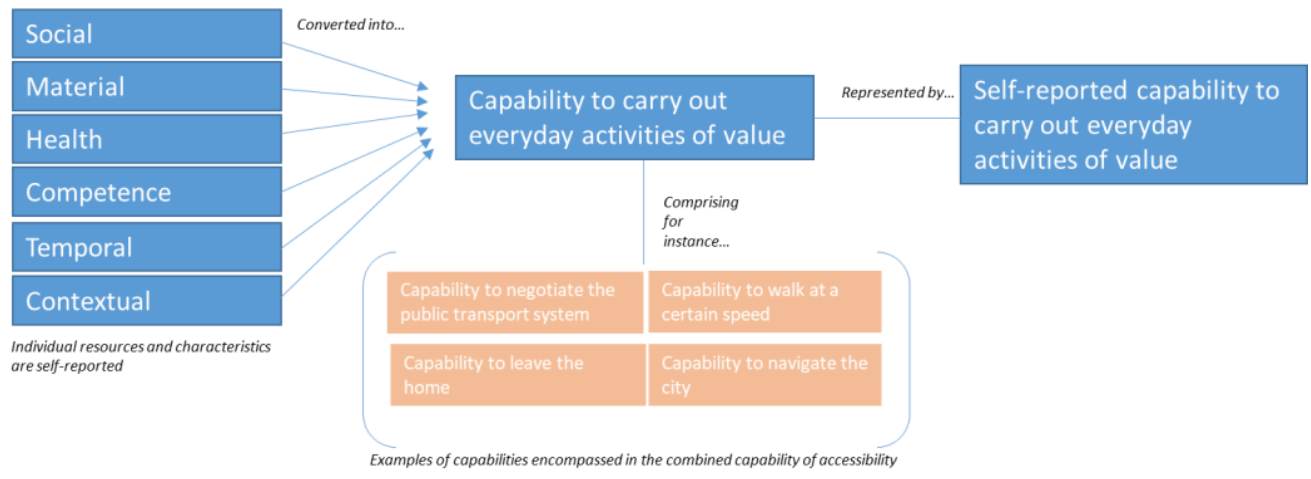

Fig. 1B Application for hypothetical analysis solely based on self-reported measure

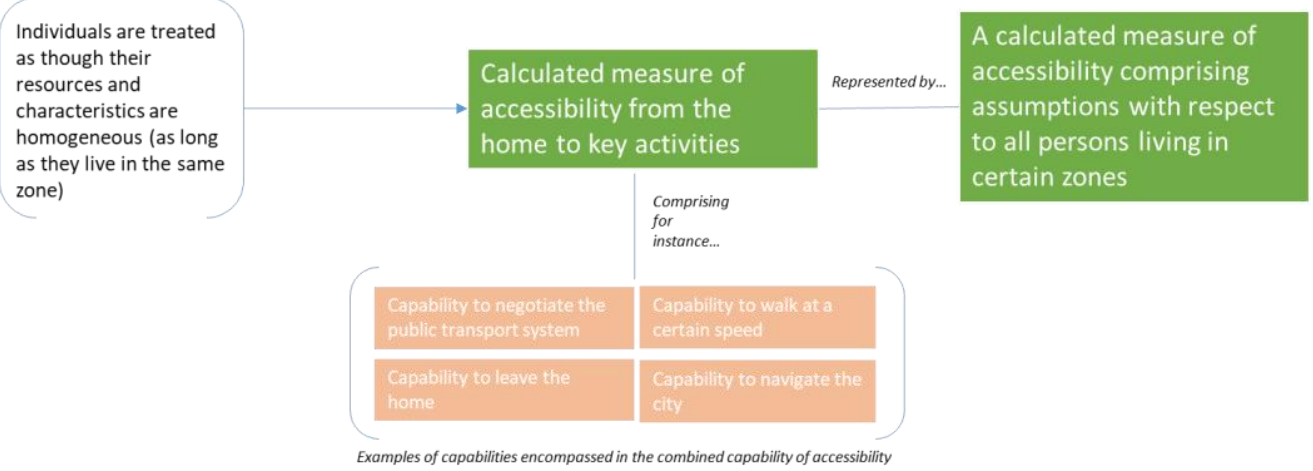

Fig. 1C Application for hypothetical analysis solely based on calculated measure

Fig. 1 Illustration of approach to analysis of accessibility as a combined capability compared to representations based solely on self-reported or calculated measures

\section{Data collection for self-reported accessibility as a capability}

The individuals' perceptions of their circumstances were compiled using a dedicated capability-based travel survey: Everyday mobility opportunities among older people living in Sweden's large metropolitan regions. This was a quantitative telephone survey comprising 1149 computer-assisted telephone interviews (CATI). The survey was based on a stratified random sample of people aged 6579 and living in Sweden's LMRs: Stockholm, Gothenburg and Malmö. This survey was designed with 
the explicit intention of capturing resources, capabilities and functionings related to accessibility and mobility, and achieved an effective response rate of 54\%. The resulting sample was largely representative of the populations in the three large metropolitan regions (see $\mathrm{X}$ for a more detailed description of this survey). See Fig. 2 for the location of the three LMRs. See Table 1 for an outline of the sample's characteristics.

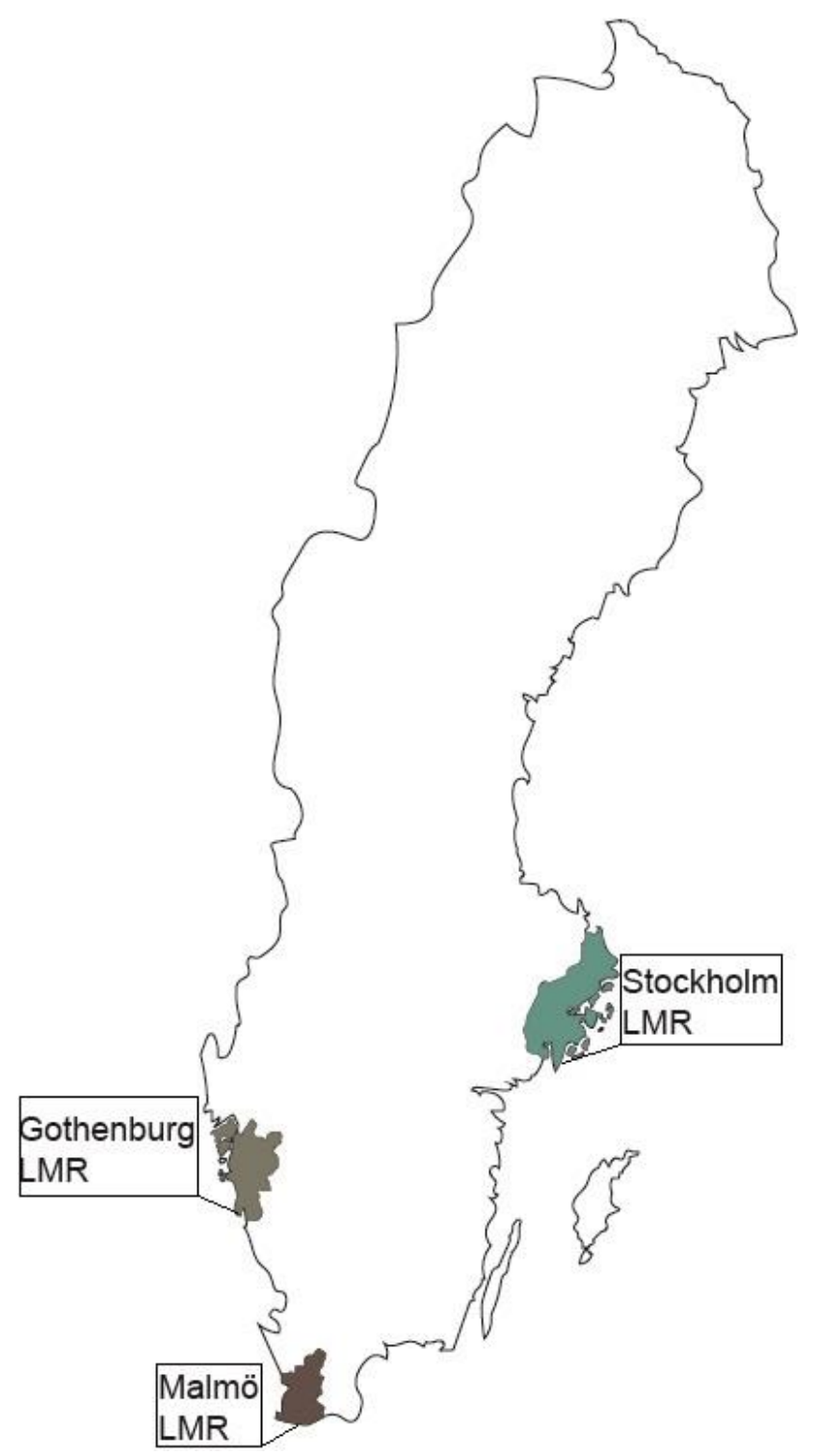

Fig. 2 Map of Sweden with the three LMRs highlighted 
Table 1 Sample characteristics (unweighted)

\begin{tabular}{|c|c|}
\hline & Frequency (percent) \\
\hline $\begin{array}{l}\text { Large metropolitan region of residence } \\
\text { Stockholm } \\
\text { Gothenburg } \\
\text { Malmö }\end{array}$ & $\begin{array}{l}383(33.3 \%) \\
383(33.3 \%) \\
383(33.3 \%)\end{array}$ \\
\hline $\begin{array}{l}\text { Age } \\
65-69 \\
70-74 \\
75-79\end{array}$ & $\begin{array}{l}441(38.4 \%) \\
435(37.9 \%) \\
273(23.8 \%)\end{array}$ \\
\hline $\begin{array}{l}\text { Gender } \\
\text { Women } \\
\text { Men }\end{array}$ & $\begin{array}{l}618(53.8 \%) \\
531(46.2 \%) \\
\end{array}$ \\
\hline $\begin{array}{l}\text { Household status } \\
\text { Cohabiting } \\
\text { Not co-habiting }\end{array}$ & $\begin{array}{l}766(66.7 \%) \\
383(33.3 \%)\end{array}$ \\
\hline $\begin{array}{l}\text { Household type } \\
\text { Living alone } \\
\text { Two-person household } \\
\text { Three or more people living together }\end{array}$ & $\begin{array}{l}369(32.1 \%) \\
732(63.7 \%) \\
47 \quad(4.1 \%)\end{array}$ \\
\hline $\begin{array}{l}\text { Subjective health status } \\
\text { Very good } \\
\text { Good } \\
\text { Neither good nor bad } \\
\text { Bad } \\
\text { Very bad }\end{array}$ & $\begin{array}{l}373(32.5 \%) \\
532(46.3 \%) \\
153(13.3 \%) \\
77 \quad(6.7 \%) \\
14 \quad(1.2 \%)\end{array}$ \\
\hline $\begin{array}{l}\text { Monthly household income (before tax) } \\
\text { Up to and including } 16,666 \text { SEK (approximately U\$1,900)* } \\
\text { Above } 16,666 \text { SEK or not stated }\end{array}$ & $\begin{array}{l}321(27.9 \%) \\
828(72.1 \%)\end{array}$ \\
\hline $\begin{array}{l}\text { Transport mode access } \\
\text { Driving license and access to a car } \\
\text { No driving license and/or access to a car } \\
\text { Access to a bike } \\
\text { No access to a bike }\end{array}$ & $\begin{array}{l}922(80.2 \%) \\
227(19.8 \%) \\
845(73.5 \%) \\
304(26.5 \%)\end{array}$ \\
\hline
\end{tabular}

A select group of respondents was asked 'Which activities would you like to carry out but cannot?'. This question was only put to those who had responded that they do not have the capability to carry out all activities of value. The activities mentioned by this group of respondents were compiled to form a typology of activities and were classified based on the activity, the specific geolocations linked to this activity, as well as type of activity in terms of flexibility and necessity ('relatively flexible versus relatively fixed in time and space' and 'relatively discretionary versus relatively necessary'). The activities outlined in Table 2 (grocery shopping and healthcare visits/appointments) were then selected based on the availability of data and according to the possibility to link specific activities to certain locations. For instance, it was not possible to geo-locate 'visiting friends and family' as the specific location of such an activity was not provided by respondents.

Table 2 Typology of activities and data sources

\begin{tabular}{|l|l|l|l|}
\hline $\begin{array}{l}\text { Type of } \\
\text { activity }\end{array}$ & \multicolumn{1}{|c|}{ Activities } & \multicolumn{1}{|c|}{ Locations } \\
\hline $\begin{array}{l}\text { Flexible- } \\
\text { necessary }\end{array}$ & Grocery shopping & Grocery stores & National grocery store database (2015) \\
\hline $\begin{array}{l}\text { Fixed- } \\
\text { necessary }\end{array}$ & $\begin{array}{l}\text { Healthcare } \\
\text { appointments }\end{array}$ & $\begin{array}{l}\text { Primary healthcare } \\
\text { centres }\end{array}$ & $\begin{array}{l}\text { Own database of primary healthcare centres } \\
\text { compiled from the respective regions' websites } \\
(2017)\end{array}$ \\
\hline
\end{tabular}

\section{Data collection for the indicator of calculated accessibility}

Two commonly used measures of accessibility were employed to give estimates of accessibility from the respondents' homes to grocery stores and healthcare centres. The first was an impedance measure: the travel time from the respondent's home to the closest activity location. The second was a traditional cumulative opportunity measure, capturing the number of grocery stores and healthcare centres that 
could be reached within a 30-minute timeframe from the location of the respondent's home. Both measures were employed using several modes and combinations of modes i.e. walking, cycling, using public transport and driving (combined with an element of walking). The impedance measure is considered to give an indication of ease, while the cumulative gives more information surrounding the extent of the choice the individuals have, even though this may be associated with marginal utility for each additional facility.

The geo-locations of these activities were obtained using a national database of supermarkets and grocery stores and three regional databases of healthcare centre geo-locations, compiled for this study. Spatial information on road networks, pedestrian and cycling infrastructure was extracted from OpenStreetMap, while public transport data organised in the General Transit Feed Specification (GTFS) format was provided by Trafiklab in Sweden. For computational purposes, geocoded data on respondents' residences, supermarkets and health centres were aggregated in a hexagonal grid of 500 by 500 metres.

The first step in calculating these accessibility measures was to estimate the travel times between every pair of grid cells by different transport modes using OpenTripPlanner (OTP). The centroids of each cell were snapped to the closest road segment within the cell and used as origins and destinations. In order to take into account for variations in transport service levels, various travel time matrices were calculated for a typical weekday, departing every 20 minutes during 07:00-08:40 (peak) and 13:00-14:40 (offpeak). These timeframes were selected based on those provided in Transport Analysis (2011); The Swedish Transport Administration (2019); and Storstockholms Lokaltrafik (2017). Accessibility estimates were calculated based on median travel times for both periods. These travel time calculations contained door-to-door estimates. In the case of a trip combining public transport and walking, for example, it considers walking time from the point of origin to the public transport stop, waiting time for the vehicle, actual travel time through the transport network, waiting time during transfers, and the walking time from the transport stop to the final destination ${ }^{1}$. When the activity was located in the same hexagonal cell as the interviewee's residence, the travel time was considered to be five minutes as a rule of thumb, regardless of transport mode. The transport modes included in the analysis were the car, walking, cycling, and a combination of public transport and walking. The calculation of total travel times also comprised maximum thresholds for walking and cycling (travel-times and distances) in order to incorporate realistic levels of physical exertion, given the age group of respondents (see Table 3). These thresholds can be described as both normative and positive (see Paez et al., 2012) as they were derived from both previous empirical research (e.g. (Asher et al., 2012; Nordbakke and Schwanen, 2015; Prins et al., 2014) and pre-existing travel survey data for Sweden (Transport Analysis, 2014). These thresholds were finite, and therefore did not account for the distribution of people taking trips among the values below the assigned thresholds. However, previous studies have noted key aspects of the way trips are distributed within said thresholds. For instance, one study found a peak in the proportion of people walking to bus stops, within the range of $200 \mathrm{~m}-400 \mathrm{~m}$, and that most walking trips take place within a $1 \mathrm{~km}$ distance (Millward et al., 2013). Although this is likely to differ from context to context.

\footnotetext{
${ }^{1}$ No penalty of making a change from one mode to another or from one vehicle to another has been included, just the absolute travel time according to the algorithms assigned by OpenTripPlanner. We have not included an 'acceptable changing time' either (aside from what is included in OpenTripPlanner's algorithm). See Djurhuus et al. (2014) for an alternative approach.
} 
Table 3 Thresholds developed for multimodal trips

\begin{tabular}{|l|l|}
\hline $\begin{array}{l}\text { Mode or multimodal } \\
\text { combination }\end{array}$ & Distance threshold \\
\hline Walking & $\leq 1500 \mathrm{~m}$ \\
\hline Public transport and walking & $\leq 1000 \mathrm{~m}$ (for walking element) \\
\hline Car and walking & $\leq 1000 \mathrm{~m}$ (for walking element) \\
\hline Bicycle & $\begin{array}{l}\leq 3000 \mathrm{~m} \text { (travel time threshold of } \leq 15 \text { minutes, must satisfy both distance and travel-time } \\
\text { threshold) }\end{array}$ \\
\hline Public transport and bicycle & $\leq 1000 \mathrm{~m}$ (for cycling element) \\
\hline
\end{tabular}

By and large, accessibility levels were higher during peak hours when compared to the off-peak estimates. However, only the off-peak estimates were ultimately included in the analyses. This was based on findings from previous studies on the travel behaviour of older people, who commonly avoid peak-hour travel (see e.g. Nordbakke, 2013; Szeto et al., 2017; Wong et al., 2018). This is usually related to greater comfort during off-peak hours and/or not wanting to feel 'in the way' by travelling during peak hours. Driving and cycling during off-peak hours is also associated with greater ease than when there are greater flows of road users (Caviedes and Figliozzi, 2018; Morris and Hirsch, 2016). Furthermore, public transport concessions for older people (if available ${ }^{2}$ ) are often subject to the condition that they be used outside of peak hours.

\section{Combination of the two measures}

The impedance measures comprised a series of variables based on travel times (continuous variables) to grocery stores and healthcare centres by different transport modes. For each mode and activity, new categorical variables were created, with the travel time values divided into two categories: those above the median value (in the respondents' respective LMRs) (less accessible) and those including and below the median value (more accessible). These variables were then compared to the respondents' reports regarding their possibilities to use modes for everyday activities. The cumulative measures comprised a series of variables based on numbers of opportunities reachable within a 30-minute timeframe. These variables were also reconstructed into categorical variables whereby the values up to and including the mean were categorised as 'fewer opportunities' and those above categorised as 'more opportunities'.

It was anticipated that there would be four groups of respondents for each type of measure, with two 'mismatch' groups among the four groups (see Fig. 2). We considered a mismatch to occur when there was an apparent disagreement between a respondent's perceptions about her possibilities to use a mode of transport for everyday activities and having a healthcare centre more or less accessible (below or above the median for each respective LMR) in terms of travel time by said mode of transport. For the cumulative analysis, we considered a mismatch to occur when there was an apparent disagreement between a respondent's perceptions about her possibilities to use a mode of transport for everyday activities and having fewer/more (below/above the mean for each respective LMR) grocery stores within a 30-minute timeframe by said mode of transport.

To examine the factors which could aid in the understanding of the occurrence of disagreements between calculated and self-reported accessibility, we conducted a series of multinomial and binary logistic regressions where the occurrence of a mismatch was used as dependent variable. Independent variables included socio-demographic characteristics and mobility and personal resources, which are known in the literature to influence travel behaviour.

\footnotetext{
${ }^{2}$ Public transport concessions for older people were not commonplace when this study was carried out. Since the study was carried out some concessions have been introduced but the type of concession as well as the conditions attached to the concession differ from municipality to municipality, and are often only available from the age of 70 and above, outside of peak hours.
} 


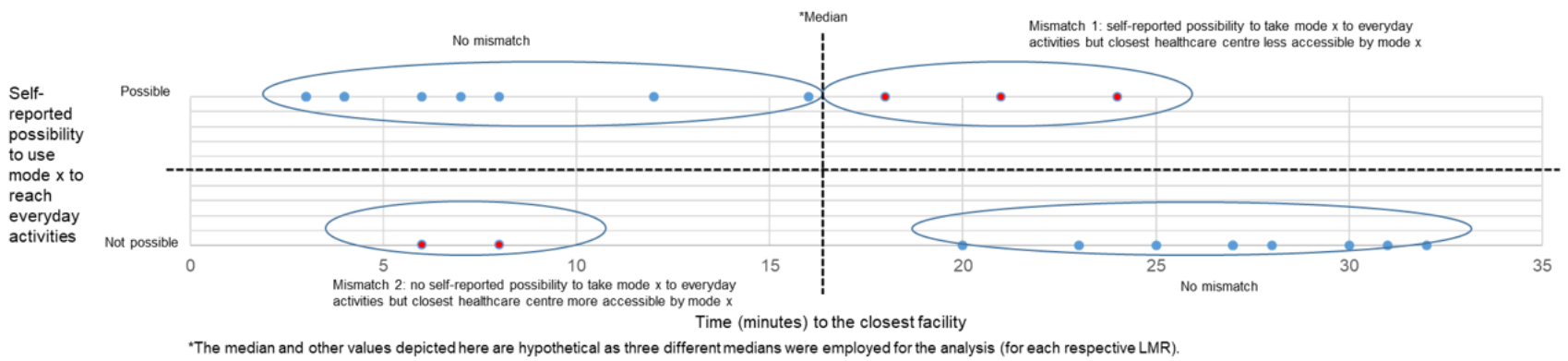

Fig. 2A Stylised depiction of impedance calculated measure to closest facility compared to self-reported possibility to use mode $x$ to reach everyday activities

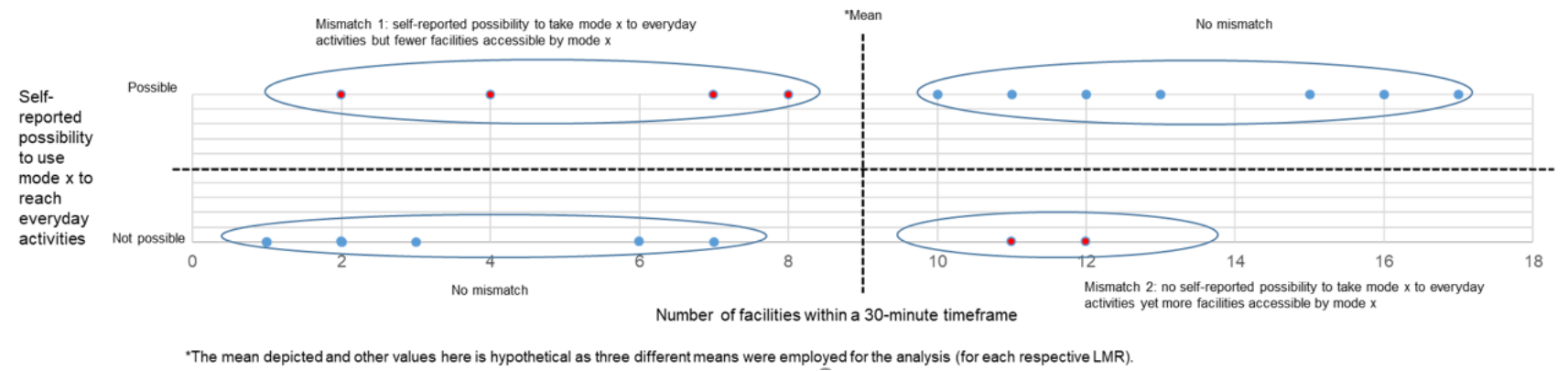

Fig. 2B Stylised depiction of the cumulative calculated measure compared to self-reported possibility to use mode $x$ to reach everyday activities

\section{Results}

The descriptive statistics for the calculated accessibility measures are presented in Figure 3.The median travel times for bicycle and for car to the closest healthcare centre are notably lower than those for walking and for a combination of using public transport and walking (Fig. 3A). It is important to emphasise that thresholds were placed on some trip types (see Table 3), influencing the duration of said trips deemed possible by the analysis. For trips to the closest grocery store, the differences between the median values are much smaller, with the results indicating that grocery stores are more numerous in comparison healthcare centres and that they may be more evenly distributed geographically. The results for the cumulative function highlight the ample possibilities provided by the car relative to other modes of transport, both in relation to healthcare centres and to grocery stores (Fig. 3B). This underscores the link between the car as a mode of transport and the freedom to choose between different facilities. Public transport, on the other hand, appears to offer far fewer possibilities, reflecting the fixity of public transport provision, even in comparison to the facilities that can be reached by bicycle and on foot. 
Fig. 3 Descriptive statistics for calculated accessibility considering closest facility (A) and cumulative opportunity measure (B) by transport mode during off-peak.

A

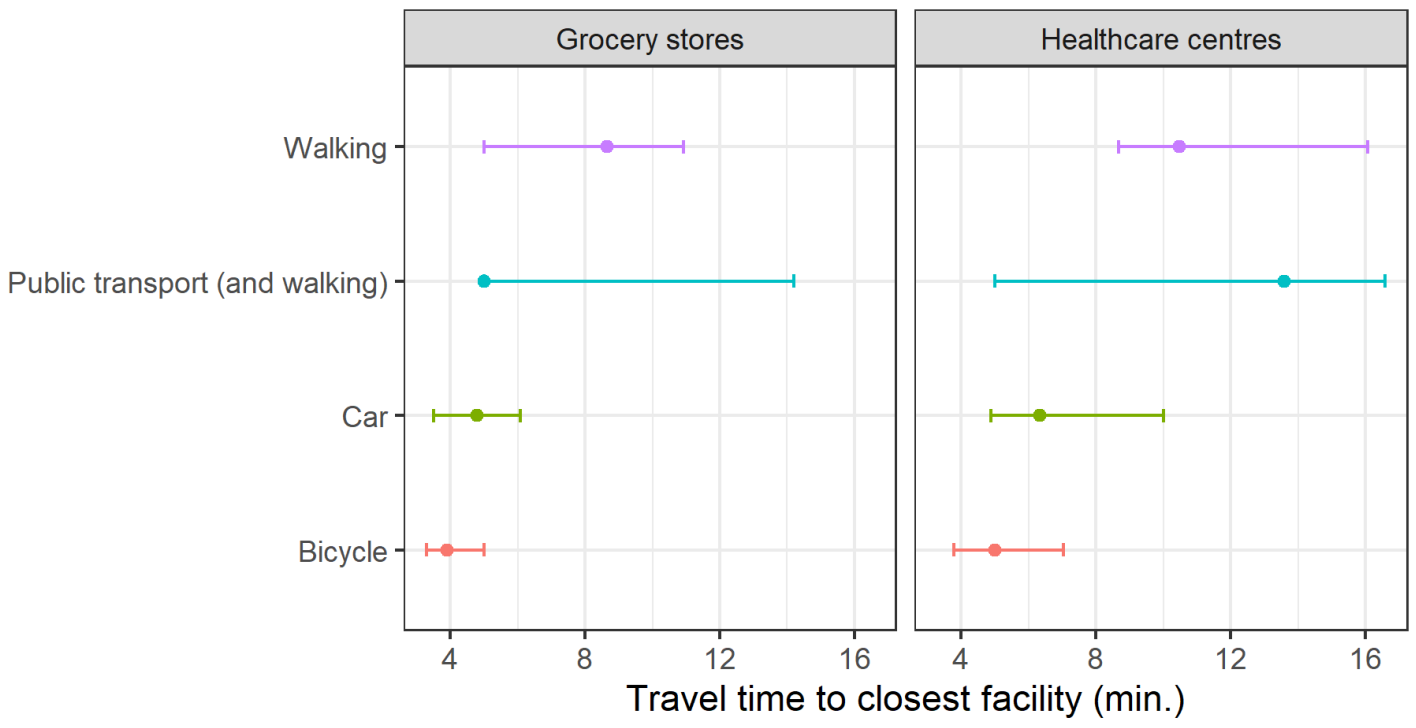

B

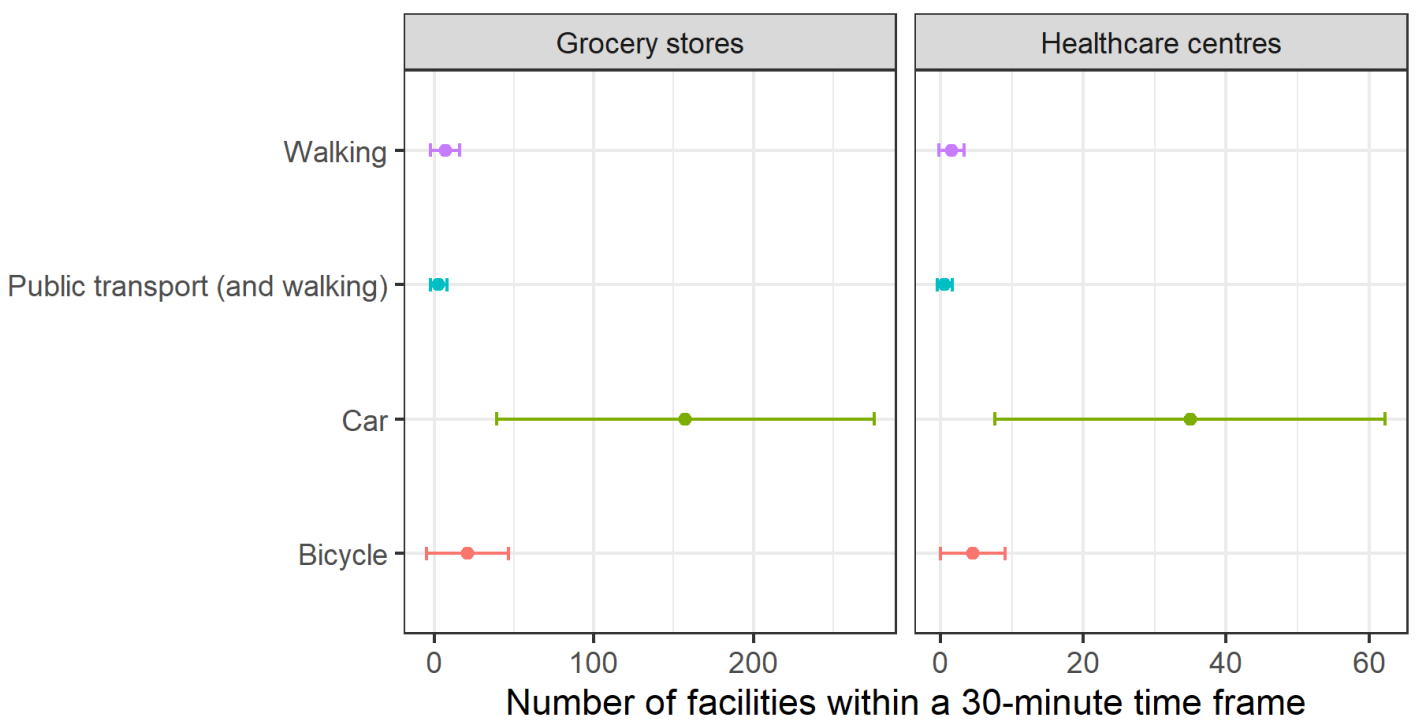

Fig. 3A displays the median and interquartile range while Fig. 3B displays the mean (+/- one standard deviation). The sample sizes differ as a result of the parameters we have applied e.g. the sample size for public transport is much smaller due to the limits we have imposed on the walking element of the public transport trip. The sample is weighted according to LMR.

The results from the survey capturing self-reported measures are presented in Table 6. Few individuals (only $8 \%$ ) declared not to have the capability to carry out all everyday activities of value, and only $2.3 \%$ declared this was due to transport-related reasons. Nonetheless, a larger proportion of people declared not having the capabilities related to use public transport (4\%), to travel by car (6.2\%), and walk (9.3\%) and bicycle (34.4\%). These variables were used as 'inputs' into the accessibility analyses, so as to reflect the perceptions of respondents and to adjust the outcomes of the analyses accordingly. 
Table 6 Self-reported measures

\begin{tabular}{|c|c|c|}
\hline \multirow{2}{*}{ Variables } & \multicolumn{2}{|c|}{$\begin{array}{l}\text { Entire sample } \\
\text { (weighted) }\end{array}$} \\
\hline & $n$ & $\%$ \\
\hline \multirow{2}{*}{$\begin{array}{l}\text { Do not have this capability (all reasons) } \\
\text { Remainder of respondents }\end{array}$} & 119 & $8.0 \%$ \\
\hline & 1362 & $92.0 \%$ \\
\hline \multirow{2}{*}{$\begin{array}{l}\text { Do not have this capability (transport and/or health-related reason) } \\
\text { Remainder of respondents }\end{array}$} & 87 & $5.9 \%$ \\
\hline & 1394 & $94.1 \%$ \\
\hline \multirow{2}{*}{$\begin{array}{l}\text { Do not have this capability (specified transport-related reason) } \\
\text { Remainder of respondents }\end{array}$} & 34 & $2.3 \%$ \\
\hline & 1448 & $97.7 \%$ \\
\hline \multirow{3}{*}{$\begin{array}{l}\text { Bicycle } \\
\text { Capability to use the bicycle as a modal option } \\
\text { Not mentioned }\end{array}$} & & \\
\hline & 972 & $65.6 \%$ \\
\hline & 509 & $34.4 \%$ \\
\hline \multirow{3}{*}{$\begin{array}{l}\text { Car (as a driver and/or passenger) } \\
\text { Capability to use the car as a modal option } \\
\text { Not mentioned }\end{array}$} & & \\
\hline & 1389 & $93.8 \%$ \\
\hline & 92 & $6.2 \%$ \\
\hline \multirow{3}{*}{$\begin{array}{l}\text { Public transport } \\
\text { Capability to use public transport as a modal option } \\
\text { Not mentioned }\end{array}$} & & \\
\hline & 1421 & $96.0 \%$ \\
\hline & 60 & $4.0 \%$ \\
\hline \multirow{3}{*}{$\begin{array}{l}\text { Walking } \\
\text { Capability to walk as a modal option } \\
\text { Not mentioned }\end{array}$} & & \\
\hline & 1343 & $90.7 \%$ \\
\hline & 138 & $9.3 \%$ \\
\hline
\end{tabular}

Figures 5 and 6 demonstrate how the results of the calculated accessibility estimates intersect with selfreported capabilities. These results indicate traditional measures of accessibility that overlook individuals' personal characteristics would overestimate the accessibility levels lived by the population. Figure 5 shows that while this overestimation is small for public transport, it is rather substantial for accessibility by bicycle due to older people's more limited capabilities to use this mode. Similarly, Figure 6 shows how traditional cumulative opportunity measures overestimate accessibility levels by assuming that all individuals are equally able to use every transport mode.

In Figures 5 and 6, and for the remainder of the analysis, we have focused on the impedance measure for trips to healthcare centres, and on the cumulative measure for trips to grocery stores. This is due to choice being a greater factor in accessibility to grocery stores compared to the former, and proximity being an arguably greater factor in accessibility to healthcare centres compared to the latter. We have also limited this part of the analysis to the modes public transport and cycling. 


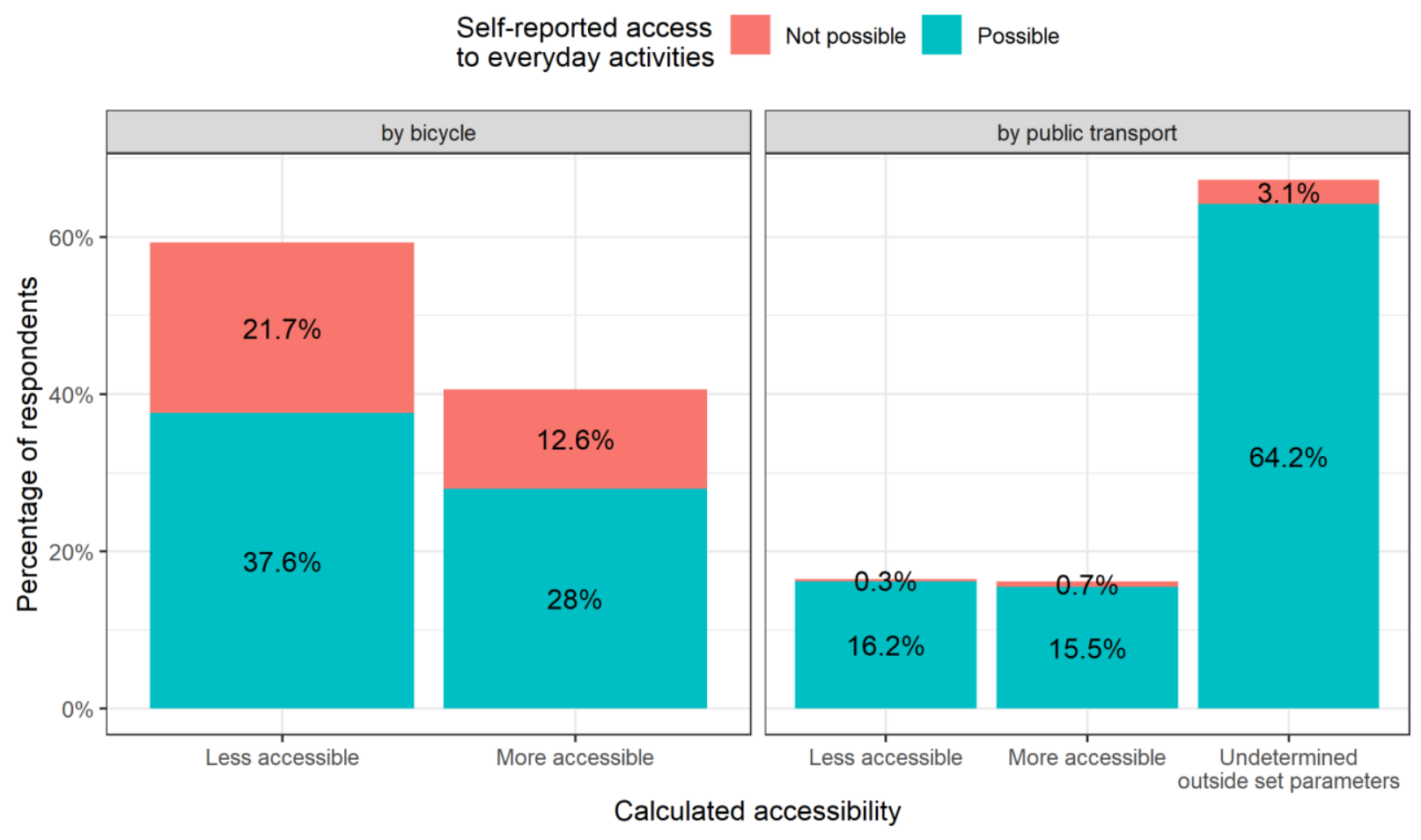

Fig.5 Accessibility to the closest healthcare centre

Self-reported access to everyday activities

Not possible Possible
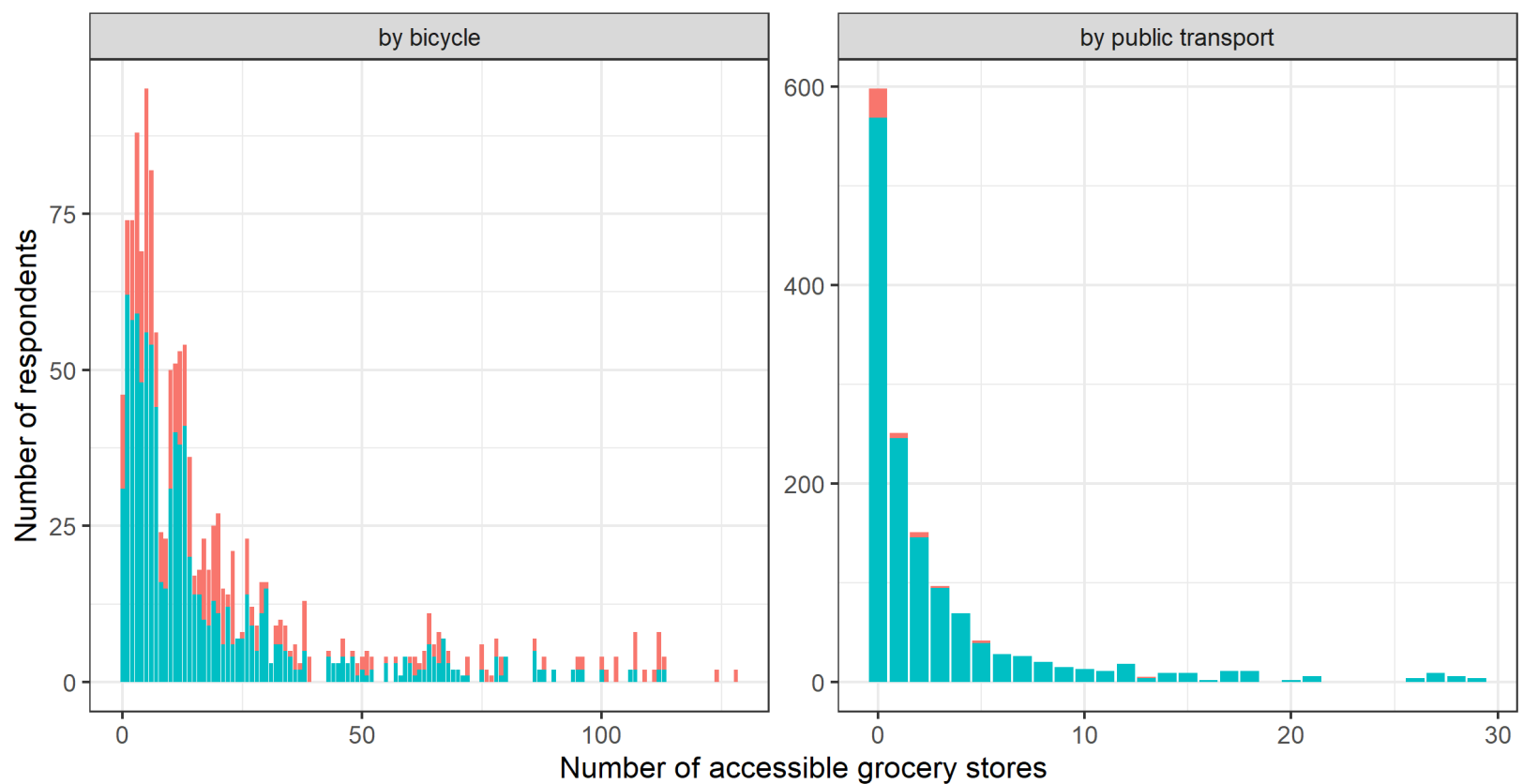

Fig. 6 Accessibility to grocery stores 
Table 7 Multinomial Logistic Regression: Analysis of instances of mismatch (accessibility by public transport to the closest healthcare centre and/or grocery store versus self-reported possibility to take public transport to everyday activities)

\begin{tabular}{|c|c|c|c|c|c|}
\hline & Independent variables & $\begin{array}{l}\text { Sig. } \\
\text { (p-value) }\end{array}$ & $\begin{array}{l}\text { Odds } \\
\text { Ratio } \\
\text { (OR) }\end{array}$ & $\begin{array}{l}95 \% \\
\text { Confidence } \\
\text { Interval (CI) } \\
\text { (lower) }\end{array}$ & $\begin{array}{l}95 \% \\
\text { Confidence } \\
\text { Interval (CI) } \\
\text { (upper) }\end{array}$ \\
\hline \multirow{5}{*}{$\begin{array}{l}\text { Group with } \\
\text { one } \\
\text { instance of } \\
\text { mismatch } \\
\text { (either } \\
\text { healthcare } \\
\text { centre or } \\
\text { grocery } \\
\text { store) }\end{array}$} & Holding a driving license and having access to a car & $<0.001$ & 0.51 & 0.36 & 0.72 \\
\hline & $\begin{array}{l}\text { Possibility to be given lifts/rides by someone else (on a } \\
\text { daily/almost daily basis) }\end{array}$ & 0.002 & 0.63 & 0.47 & 0.85 \\
\hline & Access to a bicycle & 0.360 & 0.86 & 0.63 & 1.18 \\
\hline & Cohabiting & $<0.001$ & 0.52 & 0.38 & 0.72 \\
\hline & Higher income (adjusted by LMR) & $<0.001$ & 1.78 & 1.30 & 2.44 \\
\hline \multirow{5}{*}{$\begin{array}{l}\text { Group with } \\
\text { two } \\
\text { instances } \\
\text { of } \\
\text { mismatch } \\
\text { (both } \\
\text { healthcare } \\
\text { centre and } \\
\text { grocery } \\
\text { store) }\end{array}$} & Holding a driving license and having access to a car & 0.028 & 0.62 & 0.40 & 0.95 \\
\hline & $\begin{array}{l}\text { Possibility to be given lifts/rides by someone else (on a } \\
\text { daily/almost daily basis) }\end{array}$ & $<0.001$ & 0.49 & 0.34 & 0.72 \\
\hline & Access to a bicycle & $<0.001$ & 0.44 & 0.31 & 0.63 \\
\hline & Cohabiting & 0.225 & 0.78 & 0.53 & 1.16 \\
\hline & Higher income (adjusted by LMR) & 0.135 & 1.34 & 0.91 & 1.95 \\
\hline
\end{tabular}

Reference category: No mismatch between the public transport accessibility calculated measure (to both healthcare centres and grocery stores) and reported possibility to use public transport.

Goodness-of-fit: Chi-square 66.13 (Deviance) $(\mathrm{p}=0.09) \mid$ The model was significant at a level of $\mathrm{p}<0.001 \mid-2$ Log Likelihood Intercept only: 355.47. Final: 244.57 | Pseudo R-squared: 0.10 (Nagelkerke).

Table 7 details the results from the multinomial regression with the dependent variable comprising three categories; those with no instance of mismatch (the reference category); those with one instance (to either the closest healthcare centre or grocery store) and those with two mismatches (to both locations). All else being equal, those with a driving license and access to a car; those with the possibility to be given lifts; and those who cohabit are less likely to be in the group with one instance of mismatch, relative to being in the group with no mismatch. Those with a higher income were statistically significantly more likely to be in the group with one instance of mismatch, relative to being in the group with no mismatch. These coefficient results are consistent in magnitude and direction in the analysis for two mismatches, though the statistical significance of a few variables change. These results imply that those with mobility resources (and perhaps those who travel more frequently) tend to have no, or a less apparent, mismatch. 
Table 8 Multinomial Logistic Regression: Analysis of mismatch types (accessibility by bicycle to the closest healthcare centre versus self-reported possibility to cycle to everyday activities)

\begin{tabular}{|c|c|c|c|c|c|}
\hline & Independent variables & $\begin{array}{l}\text { Sig. } \\
\text { (p-value) }\end{array}$ & $\begin{array}{l}\text { Odds } \\
\text { Ratio } \\
\text { (OR) }\end{array}$ & $\begin{array}{l}95 \% \\
\text { Confidence } \\
\text { Interval (Cl) } \\
\text { (lower) }\end{array}$ & $\begin{array}{l}95 \% \\
\text { Confidence } \\
\text { Interval (CI) } \\
\text { (upper) }\end{array}$ \\
\hline \multirow{5}{*}{$\begin{array}{l}\text { Mismatch } \\
1 \text { : self- } \\
\text { reported } \\
\text { possibility } \\
\text { to cycle to } \\
\text { everyday } \\
\text { activities } \\
\text { but closest } \\
\text { healthcare } \\
\text { centre less } \\
\text { accessible }\end{array}$} & Holding a driving license and having access to a car & $<0.001$ & 0.48 & 0.33 & 0.68 \\
\hline & Access to a bicycle & $<0.001$ & 13.80 & 7.89 & 24.12 \\
\hline & Living with another/others & 0.914 & 0.98 & 0.73 & 1.32 \\
\hline & Self-reported health rating (very good/good) & 0.023 & 1.48 & 1.06 & 2.08 \\
\hline & Gender (woman = 1) & 0.121 & 1.23 & 0.95 & 1.60 \\
\hline \multirow{5}{*}{$\begin{array}{l}\text { Mismatch } \\
\text { 2: no self- } \\
\text { reported } \\
\text { possibility } \\
\text { to cycle but } \\
\text { closest } \\
\text { healthcare } \\
\text { centre } \\
\text { more } \\
\text { accessible }\end{array}$} & Holding a driving license and having access to a car & 0.806 & 1.06 & 0.68 & 1.63 \\
\hline & Access to a bicycle & $<0.001$ & 0.09 & 0.06 & 0.14 \\
\hline & Living with another/others & $<0.001$ & 2.33 & 1.54 & 3.52 \\
\hline & Self-reported health rating (very good/good) & 0.330 & 0.83 & 0.56 & 1.21 \\
\hline & Gender $($ woman $=1)$ & 0.034 & 1.51 & 1.03 & 2.22 \\
\hline
\end{tabular}

Reference category: No mismatch between the cycling accessibility calculated measure to the closest healthcare centre and the self-reported possibility to cycle to everyday activities.

Goodness-of-fit: Chi-square 93.26 (Deviance) ( $\mathrm{p}<0.001) \mid$ The model was significant at a level of $\mathrm{p}<0.001 \mid-2$ Log Likelihood Intercept only: 684.94. Final: 246.08 | Pseudo R-squared: 0.31 (Nagelkerke).

Table 8 outlines the results for the analysis of types of mismatch with respect to cycling to the closest healthcare centre. Here, the dependent variable comprises three categories: no mismatch (reference category), mismatch type 1; and mismatch type 2 . Similar to the results detailed in Table 7 , holding a driving license and having access to a car is associated with a lower likelihood of being in the group with a mismatch (here type 1). Those who have access to a bicycle are almost 14 times as likely to be in the group with a self-reported possibility to cycle to everyday activities despite the closest healthcare centre being less accessible than for others. While those with a high self-reported health rating are approximately one-and-a-half-times as likely to be in this same group. On the other hand, those with access to a bicycle are much less likely to be in the group with no self-reported possibility to cycle even though the closest healthcare centre is more accessible by bicycle (according to the calculated measure). Those who live with at least one other person are more than twice as likely as those living alone, while women are one-and-a-half-times more likely than men to be in the group with mismatch type 2 . The results for access to a bicycle seem to be related to having a greater scope for action, that is, having the perception that it is possible to cycle to everyday activities despite perhaps a lower calculated accessibility level. While a high self-reported health rating seems to be linked to this same type of perception. The link between being a woman and increased odds of being in the group with mismatch is not surprising given that fewer women perceive they can cycle and actually do cycle in this age group when compared to men (J. Ryan et al., 2016). 
Table 9 Multinomial Logistic Regression: Analysis of mismatch types (accessibility by bicycle to grocery stores versus self-reported possibility to cycle to everyday activities)

\begin{tabular}{|c|c|c|c|c|c|}
\hline & Independent variables & $\begin{array}{l}\text { Sig. } \\
\text { (p-value) }\end{array}$ & $\begin{array}{l}\text { Odds } \\
\text { Ratio } \\
\text { (OR) }\end{array}$ & $\begin{array}{l}95 \% \\
\text { Confiden } \\
\text { ce } \\
\text { Interval } \\
\text { (Cl) } \\
\text { (lower) }\end{array}$ & $\begin{array}{l}95 \% \\
\text { Confidence } \\
\text { Interval (CI) } \\
\text { (upper) }\end{array}$ \\
\hline \multirow{3}{*}{$\begin{array}{l}\text { Mismatch 1: self- } \\
\text { reported possibility to } \\
\text { cycle to everyday } \\
\text { activities but fewer } \\
\text { grocery stores } \\
\text { accessible by bicycle }\end{array}$} & $\begin{array}{l}\text { Holding a driving license and having access } \\
\text { to a car }\end{array}$ & 0.001 & 1.82 & 1.28 & 2.59 \\
\hline & Access to a bicycle & $<0.001$ & 85.64 & 39.92 & 183.75 \\
\hline & $\begin{array}{l}\text { Experiencing health problems less often (less } \\
\text { than once a day) }\end{array}$ & 0.054 & 1.81 & 0.99 & 3.30 \\
\hline \multirow{3}{*}{$\begin{array}{l}\text { Mismatch 2: no self- } \\
\text { reported possibility to } \\
\text { cycle yet more } \\
\text { grocery stores } \\
\text { accessible by bicycle }\end{array}$} & $\begin{array}{l}\text { Holding a driving license and having access } \\
\text { to a car }\end{array}$ & $<0.001$ & 0.46 & 0.31 & 0.66 \\
\hline & Access to a bicycle & $<0.001$ & 0.17 & 0.11 & 0.27 \\
\hline & $\begin{array}{l}\text { Experiencing health problems less often (less } \\
\text { than once a day) }\end{array}$ & 0.009 & 2.28 & 1.23 & 4.25 \\
\hline
\end{tabular}

Reference category: No mismatch between the cycling accessibility calculated measure to grocery stores and the self-reported possibility to cycle to everyday activities.

Goodness-of-fit: Chi-square 9.56 (Deviance) $(\mathrm{p}=0.30) \mid$ The model was significant at a level of $\mathrm{p}<0.001 \mid-2$ Log Likelihood Intercept only: 852.73. Final: 63.10 | Pseudo R-squared: 0.50 (Nagelkerke).

Table 9 presents the analysis of mismatch types in relation to the cumulative measure to grocery stores, with the dependent variable comprising three categories: no mismatch (reference category); mismatch 1 ; and mismatch 2 . Here, the variables of holding a driving license and having access to a car; and having access to a bicycle were associated with higher odds of being in the group with mismatch 1 . Access to a bicycle was particularly relevant in the analysis of this mismatch, given that those with said access were close to 86 times as likely to have this mismatch compared to having no mismatch. The same variables were associated with a lower likelihood of having a 'mismatch 2'. Those who experience health problems less often were on the other hand more likely to have a mismatch of no self-reported possibility to cycle yet more grocery stores accessible by bicycle, which was a somewhat unexpected result. 
Table 10 Binary Logistic Regression: Analysis of mismatch types (accessibility by public transport to grocery stores versus self-reported possibility to take public transport to everyday activities)

\begin{tabular}{|c|c|c|c|c|c|}
\hline & Independent variables & $\begin{array}{l}\text { Sig. } \\
\text { (p-value) }\end{array}$ & $\begin{array}{l}\text { Odds } \\
\text { Ratio } \\
\text { (OR) }\end{array}$ & $\begin{array}{l}95 \% \\
\text { Confiden } \\
\text { ce } \\
\text { Interval } \\
\text { (Cl) } \\
\text { (lower) }\end{array}$ & $\begin{array}{l}95 \% \\
\text { Confidence } \\
\text { Interval (Cl) } \\
\text { (upper) }\end{array}$ \\
\hline \multirow{6}{*}{$\begin{array}{l}\text { Mismatch 1: self- } \\
\text { reported possibility to } \\
\text { take public transport } \\
\text { to everyday activities } \\
\text { but fewer grocery } \\
\text { stores accessible by } \\
\text { public transport }\end{array}$} & $\begin{array}{l}\text { Holding a driving license and having access } \\
\text { to a car }\end{array}$ & $<0.001$ & 3.11 & 1.70 & 5.70 \\
\hline & Access to a bicycle & $<0.001$ & 4.46 & 2.54 & 7.83 \\
\hline & Number of people in the household & 0.038 & 0.61 & 0.38 & 0.97 \\
\hline & Age categorical $(65-74=1 ; 75-79=0)$ & 0.033 & 1.82 & 1.05 & 3.18 \\
\hline & Self-reported health rating (very good/good) & $<0.001$ & 2.79 & 1.62 & 4.83 \\
\hline & $\begin{array}{l}\text { Income }(\leq 16666 \text { SEK/month }=0 ; \geq 16667 \\
\text { SEK/month /other }=1)\end{array}$ & 0.018 & 0.46 & 0.24 & 0.87 \\
\hline
\end{tabular}

Reference category: No mismatch between the public transport accessibility calculated measure to grocery stores and the selfreported possibility to take public transport to everyday activities.

Hosmer and Lemeshow Test Chi-square $4.72(\mathrm{p}=0.69) \mid$ The model was significant at a level of $\mathrm{p}<0.001$ |Pseudo R-squared: 0.20 (Nagelkerke).

Finally, the results from Table 10 highlight that the same variables of holding a driving license and having access to a car and access to a bicycle are associated with higher odds of being in the group with a mismatch (the only type of mismatch presenting for this analysis). Those in the younger age range as well as those with a high self-reported health rating were more likely to have this mismatch as opposed to no mismatch, while a higher income is associated with a higher odds of having no mismatch in this instance.

\section{Discussion}

The aim of this study was to examine (1) the characteristics of both calculated and self-reported accessibility accounts; (2) whether and how these two accounts differ; and (3) the systematic mechanisms behind these differences. The results of this study give us a greater insight into the ways in which these two accounts can complement one another and the differences in the characteristics of both self-reported ('subjective') and calculated ('objective') accessibility among this group of older people. Exploring the differences between the two accounts assists us in uncovering potential reasons as to why findings based on one or the other approach can differ and how including both approaches can assist in overcoming such methodological difficulties.

When comparing self-reported accounts of modal options and calculated accessibility, the results suggest that conventional accessibility measures tend to overestimate accessibility levels and underestimate accessibility inequalities by assuming that all individuals are equally capable of using a given transport mode. We found that cycling is more sensitive to such inaccuracies when compared to public transport-based accessibility analyses. This is partly owing to a larger proportion of respondents stating that they cannot cycle compared to the proportion stating that they cannot use public transport. The results for the public transport calculated measure as such correspond more closely to the respondents' self-reported accounts of access to modes for everyday activities. This could also be related to the tailored thresholds employed for these analyses (cf. Millward et al., 2013; Páez et al., 2012) and 
due to the relatively widely implemented adaptation of infrastructure to passengers with mobility restrictions.

Results from the analysis of instances of mismatch indicate that those with mobility resources are less likely to have a mismatch between the self-reported and calculated accessibility accounts. Having mobility resources may overlap with travelling more frequently and thus having more familiarity with the locality, or indeed, with that particular mode of transport and the accessibility to everyday activities it conveys (see Curl et al., 2015).

Those who have access to a bicycle are almost 14 times as likely to be in the group with a self-reported possibility to cycle to everyday activities despite the closest healthcare centre being less accessible than for others (mismatch type 1). This indicates that habitual cyclists perceive that it is possible to cycle to everyday activities despite a lower calculated accessibility level. A high self-reported health rating is associated with this same type of perception. These effects could be related to the individual's perceived scope for action drawing on the nexus between them having both access to an actual bicycle, as well as the fitness level and functional capacity required to cycle it, albeit to activities which may lie further afield than for others. Having access to a bicycle, living with another/others and gender produced significant results in relation to the likelihood of having a mismatch type 2 . However, here bicycle access was related to a lower likelihood of being in this group, with the other two variables associated with a higher likelihood. The link between being a woman and increased odds of being in the group with a mismatch is not surprising given that fewer women perceive they can cycle and actually do cycle in this age group when compared to men (J. Ryan et al., 2016). This perception is perhaps not necessarily linked to proximity to activities by bicycle but instead to gendered differences with respect to perceptions of infrastructure quality (Aldred et al., 2016) or social and personal norms (Prati, 2018), which in turn could be related to adaptive preferences.

Potential adaptive preference effects in self-reported accounts (Nussbaum, 2001) compel us to not only consider the perceptions of individuals, but also how these may be affected by adjusted expectations. This implies that we must look beyond satisfaction with activities in order to ensure that the development of real capabilities can be supported (see Curl et al., 2011; Stanley and Vella-Brodrick, 2009). This is of particular importance for this age group, as ageing is often associated with adaptive preference effects (see Baltes and Baltes, 1990: 7-8). The results from this paper show that when the heterogeneity of personal characteristics and perceptions is overlooked, not only are accessibility levels overestimated for some people, but the differences between individuals are underestimated as well (see Ferreira and Batey 2007; Salonen et al., 2012). Moreover, it shows that traditional accessibility methods commonly used in academic and policy settings can further amplify such discrepancies in the estimation of accessibility levels by overlooking the heterogeneity in people's perceptions of their accessibility (see Laatikainen et al. 2015). Although our study focused on older people, we believe this approach could be adapted to other social groups and that the conclusions of this study could be valid for more general populations.

The employment of the Capability Approach as a framework compels us to focus on heterogeneity in resources and characteristics, which are considered to affect capabilities. It also requires us to consider individuals' perception of their own situation more seriously. The individual's perception of their own capability is said to affect whether or not - and the ways in which - it can be operationalised. If the observer deems a certain activity or location as 'accessible' for an individual, and if that same individual, due to insufficient income, lack of modal options or time constraints, considers that this activity is inaccessible, does it matter what the observer has observed? Is a capability a real opportunity if the individual does not perceive that it is possible to realise it? According to Sen, perhaps not (see e.g. Sen (1995: 52-53)).

Transport accessibility studies are generally based on averages and uniform assumptions across populations (Miller, 2018), which tend to neglect the transport experiences of older people.. The 'cutoff' point for what is accessible or not is usually somewhat arbitrary. We tailored several of the parameters (such as walking and cycling distance thresholds and speeds) to this age group. However, these parameters are still not likely to be realistic for every person within this group. Given that it is not possible to give just one value to indicate a level of accessibility across activities and across individuals, 
times of day and modes of transport, it is perhaps more apt to use the plural 'accessibilities' to describe what is being measured (cf. Haugen, 2011). A large number of variables with many potential cut-off points and thresholds present difficulties in finding links between subjective and objective indicators in terms of the capability to participate in everyday activities of value (Lättman et al., 2018). Moreover, further research would be necessary to understand whether and how local context and built environment characteristics influence the relationship between self-reported and calculated accessibility, something we could not do due to sample size limitations.

Similar to the findings from Laatikainen et al. (2015), we argue that examining accessibility is far from a straightforward process. The use of arbitrary or normative distance or travel time thresholds are likely to result in problematic comparisons. A fine-grained and tailored approach is required in order to produce more comparable results (see Laatikainen et al., 2015; Salonen et al., 2012; Salonen and Toivonen, 2013). Although here we have found that there can still be discrepancies even when efforts are made to improve the granularity of the approaches, tailored to older people in the population.

The ageing process is often associated with having fewer modal options (J. Ryan et al., 2016; Siren and Haustein, 2015). This in turn results in older people having lower levels of accessibility to everyday outof-home activities. Accessibility analyses accounting for the circumstances of groups such as older people, as well as including their perspectives are necessary in order to gain a more nuanced understanding of how accessibility differs for different groups of people. Accounting for the fact that some cannot use certain modes, and tailoring thresholds and activities of importance are among key aspects that should therefore be considered.

The results of our study have reinforced the notion that accessibility is not purely spatial, and is intertwined with the individual and her subjective perceptions of her own capabilities. When developing accessibility analyses to inform policy changes, analysts should ideally consider more realistic methods that account for how individuals' characteristics and self-reported accessibility interact with calculated accessibility measurements. When this is not possible, it is crucial to acknowledge what would be 'missing' when relying solely on self-reported or calculated accounts of accessibility. With a better understanding of what might be missing and why, policies can be targeted in a more nuanced, informed and arguably, more effective, way.

\section{References}

Aldred, R., Woodcock, J., Goodman, A., 2016. Does More Cycling Mean More Diversity in Cycling? Transp. Rev. 36, 28-44. https://doi.org/10.1080/01441647.2015.1014451

Asher, L., Aresu, M., Falaschetti, E., Mindell, J., 2012. Most older pedestrians are unable to cross the road in time: A cross-sectional study. Age Ageing 41, 690-694. https://doi.org/10.1093/ageing/afs076

Beyazit, E., 2011. Evaluating social justice in transport: Lessons to be learned from the capability approach. Transp. Rev. 31, 117-134. https://doi.org/10.1080/01441647.2010.504900

Bocarejo S., J.P., Oviedo H., D.R., 2012. Transport accessibility and social inequities: a tool for identification of mobility needs and evaluation of transport investments. J. Transp. Geogr. 24, 142-154. https://doi.org/10.1016/j.jtrangeo.2011.12.004

Bohte, W., Maat, K., van Wee, B., 2009. Measuring attitudes in research on residential self-selection and travel behaviour: A review of theories and empirical research. Transp. Rev. 29, 325-357. https://doi.org/10.1080/01441640902808441

Boisjoly, G., El-Geneidy, A.M., 2017. How to get there? A critical assessment of accessibility objectives and indicators in metropolitan transportation plans. Transp. Policy 55, 38-50. https://doi.org/10.1016/j.tranpol.2016.12.011

Caviedes, A., Figliozzi, M., 2018. Modeling the impact of traffic conditions and bicycle facilities on cyclists' on-road stress levels. Transp. Res. Part F Traffic Psychol. Behav. 58, 488-499. 
https://doi.org/10.1016/j.trf.2018.06.032

Chen, X., Kwan, M.P., 2012. Choice set formation with multiple flexible activities under space-time constraints. Int. J. Geogr. Inf. Sci. 26, 941-961. https://doi.org/10.1080/13658816.2011.624520

Curl, A., Nelson, J.D., Anable, J., 2015. Same question, different answer: A comparison of GIS-based journey time accessibility with self-reported measures from the National Travel Survey in England. Comput. Environ. Urban Syst. 49, 86-97. https://doi.org/10.1016/j.compenvurbsys.2013.10.006

Curl, A., Nelson, J.D., Anable, J., 2011. Does accessibility planning address what matters? A review of current practice and practitioner perspectives. Res. Transp. Bus. Manag. 2, 3-11. https://doi.org/10.1016/j.rtbm.2011.07.001

Dijst, M., de Jong, T., van Eck, J.R., 2002. Opportunities for transport mode change: An exploration of a disaggregated approach. Environ. Plan. B Plan. Des. 29, 413-430. https://doi.org/10.1068/b12811

Djurhuus, S., Hansen, H.S., Aadahl, M., Glümer, C., 2014. The association between access to public transportation and self-reported active commuting. Int. J. Environ. Res. Public Health 11, 1263212651. https://doi.org/10.3390/ijerph111212632

Farber, S., Neutens, T., Miller, H.J., Li, X., 2013. The Social Interaction Potential of Metropolitan Regions: A Time-Geographic Measurement Approach Using Joint Accessibility. Ann. Assoc. Am. Geogr. 103, 483-504. https://doi.org/10.1080/00045608.2012.689238

Geurs, K.T., Östh, J., 2016. Advances in the measurement of transport impedance in accessibility modelling. Eur. J. Transp. Infrastruct. Res. 16, 294-299. https://doi.org/10.18757/ejtir.2016.16.2.3138

Geurs, K.T., van Wee, B., 2004. Accessibility evaluation of land-use and transport strategies: Review and research directions. J. Transp. Geogr. 12, 127-140. https://doi.org/10.1016/j.jtrangeo.2003.10.005

Gil Solá, A., Vilhelmson, B., Larsson, A., 2018. Understanding sustainable accessibility in urban planning: Themes of consensus, themes of tension. J. Transp. Geogr. 70, 1-10. https://doi.org/10.1016/j.jtrangeo.2018.05.010

Hägerstrand, T., 1989. Reflections on "what about people in regional science?" Pap. Reg. Sci. Assoc. https://doi.org/10.1007/BF01954291

Handy, S., 2020. Is accessibility an idea whose time has finally come? Transp. Res. Part D Transp. Environ. 83, 102319. https://doi.org/10.1016/j.trd.2020.102319

Haugen, K., 2011. The advantage of "near": Which accessibilities matter to whom? Eur. J. Transp. Infrastruct. Res. 11, 368-388. https://doi.org/10.18757/ejtir.2011.11.4.2941

Hickman, R., Cao, M., Lira, B.M., Fillone, A., Biona, J.B., 2017. Understanding capabilities, functionings and travel in high and low income neighbourhoods in manila. Soc. Incl. 5, 161-174. https://doi.org/10.17645/si.v5i4.1083

Laatikainen, T., Tenkanen, H., Kyttä, M., Toivonen, T., 2015. Comparing conventional and PPGIS approaches in measuring equality of access to urban aquatic environments. Landsc. Urban Plan. 144, 22-33. https://doi.org/10.1016/j.landurbplan.2015.08.004

Lättman, K., Olsson, L.E., Friman, M., 2018. A new approach to accessibility - Examining perceived accessibility in contrast to objectively measured accessibility in daily travel. Res. Transp. Econ. 69, 501-511. https://doi.org/10.1016/j.retrec.2018.06.002

Lättman, K., Olsson, L.E., Friman, M., 2016. Development and test of the Perceived Accessibility Scale (PAC) in public transport. J. Transp. Geogr. 54, 257-263. 
https://doi.org/10.1016/j.jtrangeo.2016.06.015

Mahmoudi, M., Song, Y., Miller, H.J., Zhou, X., 2019. Accessibility with time and resource constraints: Computing hyper-prisms for sustainable transportation planning. Comput. Environ. Urban Syst. 73, 171-183. https://doi.org/10.1016/j.compenvurbsys.2018.10.002

Mercado, R., Páez, A., Newbold, K.B., 2010. Transport policy and the provision of mobility options in an aging society: A case study of Ontario, Canada. J. Transp. Geogr. 18, 649-661. https://doi.org/10.1016/j.jtrangeo.2010.03.017

Miller, E.J., 2018. Accessibility: measurement and application in transportation planning. Transp. Rev. 38, 551-555. https://doi.org/10.1080/01441647.2018.1492778

Millward, H., Spinney, J., Scott, D., 2013. Active-transport walking behavior: Destinations, durations, distances. J. Transp. Geogr. 28, 101-110. https://doi.org/10.1016/j.jtrangeo.2012.11.012

Mollenkopf, H., Hieber, A., Wahl, H.W., 2011. Continuity and change in older adults' perceptions of out-of-home mobility over ten years: A qualitative-quantitative approach. Ageing Soc. 31, 782802. https://doi.org/10.1017/S0144686X10000644

Morris, E.A., Hirsch, J.A., 2016. Does rush hour see a rush of emotions? Driver mood in conditions likely to exhibit congestion. Travel Behav. Soc. 5, 5-13. https://doi.org/10.1016/j.tbs.2015.07.002

Murray, L., 2014. Age-friendly mobilities: A transdisciplinary and intergenerational perspective. J. Transp. Heal. 2, 302-307. https://doi.org/10.1016/j.jth.2015.02.004

Nordbakke, S., 2013. Capabilities for mobility among urban older women: barriers, strategies and options. J. Transp. Geogr. 26, 166-174. https://doi.org/10.1016/j.jtrangeo.2012.10.003

Nordbakke, S., Schwanen, T., 2015. Transport, unmet activity needs and wellbeing in later life: exploring the links. Transportation (Amst). 42, 1129-1151. https://doi.org/10.1007/s11116-0149558-x

Nordbakke, S., Schwanen, T., 2014. Well-being and Mobility: A Theoretical Framework and Literature Review Focusing on Older People. Mobilities 9, 104-129. https://doi.org/10.1080/17450101.2013.784542

Nussbaum, M.C., 2001. Symposium on Amartya Sen's philosophy: 5 Adaptive preferences and women's options. Econ. Philos. 17, 67-88. https://doi.org/10.1017/S0266267101000153

Páez, A., Scott, D.M., Morency, C., 2012. Measuring accessibility: Positive and normative implementations of various accessibility indicators. J. Transp. Geogr. 25, 141-153. https://doi.org/10.1016/j.jtrangeo.2012.03.016

Patterson, Z., Farber, S., 2015. Potential Path Areas and Activity Spaces in Application: A Review. Transp. Rev. 35, 679-700. https://doi.org/10.1080/01441647.2015.1042944

Pereira, R.H.M., Schwanen, T., Banister, D., 2017. Distributive justice and equity in transportation. Transp. Rev. 37, 170-191. https://doi.org/10.1080/01441647.2016.1257660

Prati, G., 2018. Gender equality and women's participation in transport cycling. J. Transp. Geogr. 66, 369-375. https://doi.org/10.1016/j.jtrangeo.2017.11.003

Prins, R.G., Pierik, F., Etman, A., Sterkenburg, R.P., Kamphuis, C.B.M., van Lenthe, F.J., 2014. How many walking and cycling trips made by elderly are beyond commonly used buffer sizes: Results from a GPS study. Heal. Place 27, 127-133. https://doi.org/10.1016/j.healthplace.2014.01.012

Ryan, J., Svensson, H., Rosenkvist, J., Schmidt, S.M., Wretstrand, A., 2016. Cycling and cycling cessation in later life: Findings from the city of Malmö. J. Transp. Heal. 3. https://doi.org/10.1016/j.jth.2016.01.002 
Ryan, J., Wretstrand, A., 2019. What's mode got to do with it? Exploring the links between public transport and car access and opportunities for everyday activities among older people. Travel Behav. Soc. https://doi.org/10.1016/j.tbs.2018.10.003

Ryan, J., Wretstrand, A., Schmidt, S.M., 2019. Disparities in mobility among older people: Findings from a capability-based travel survey. Transp. Policy 79, 177-192. https://doi.org/10.1016/j.tranpol.2019.04.016

Ryan, J., Wretstrand, A., Schmidt, S.M., 2015. Exploring public transport as an element of older persons' mobility: A Capability Approach perspective. J. Transp. Geogr. 48. https://doi.org/10.1016/j.jtrangeo.2015.08.016

Ryan, M., Lin, T.G., Xia, J.C., Robinson, T., 2016. Comparison of perceived and measured accessibility between different age groups and travel modes at Greenwood Station, Perth, Australia. Eur. J. Transp. Infrastruct. Res. 16, 406-423. https://doi.org/10.18757/ejtir.2016.16.2.3145

Salonen, M., Toivonen, T., 2013. Modelling travel time in urban networks: Comparable measures for private car and public transport. J. Transp. Geogr. 31, 143-153. https://doi.org/10.1016/j.jtrangeo.2013.06.011

Salonen, M., Toivonen, T., Cohalan, J.M., Coomes, O.T., 2012. Critical distances: Comparing measures of spatial accessibility in the riverine landscapes of Peruvian Amazonia. Appl. Geogr. 32, 501-513. https://doi.org/10.1016/j.apgeog.2011.06.017

Scheiner, J., Holz-Rau, C., 2007. Travel mode choice: Affected by objective or subjective determinants? Transportation (Amst). 34, 487-511. https://doi.org/10.1007/s11116-007-9112-1

Schmöcker, J.D., Quddus, M.A., Noland, R.B., Bell, M.G.H., 2008. Mode choice of older and disabled people: a case study of shopping trips in London. J. Transp. Geogr. 16, 257-267. https://doi.org/10.1016/j.jtrangeo.2007.07.002

Schwanen, T., 2008. Struggling with time: Investigating coupling constraints. Transp. Rev. 28, 337 356. https://doi.org/10.1080/01441640701642363

Shen, Qingyun, Levine, J., Grengs, J., Shen, Qng, 2012. Does accessibility require density or speed? J. Am. Plan. Assoc. 78, 157-172. https://doi.org/10.1080/01944363.2012.677119

Silva, C., Bertolini, L., te Brömmelstroet, M., Milakis, D., Papa, E., 2017. Accessibility instruments in planning practice: Bridging the implementation gap. Transp. Policy 53, 135-145. https://doi.org/10.1016/j.tranpol.2016.09.006

Siren, A., Haustein, S., 2015. What are the impacts of giving up the driving licence? Ageing Soc. 35, 1821-1838. https://doi.org/10.1017/S0144686X14000610

Spinney, J.E.L., Scott, D.M., Newbold, K.B., 2009. Transport mobility benefits and quality of life: A time-use perspective of elderly Canadians. Transp. Policy 16, 1-11. https://doi.org/10.1016/j.tranpol.2009.01.002

Stanley, J., Vella-Brodrick, D., 2009. The usefulness of social exclusion to inform social policy in transport. Transp. Policy 16, 90-96. https://doi.org/10.1016/j.tranpol.2009.02.003

Storstockholms Lokaltrafik, 2017. Fakta om SL och länet 2016. Trafikförvaltningen Stockholms läns landsting S-2016-0762.

Szeto, W.Y., Yang, L., Wong, R.C.P., Li, Y.C., Wong, S.C., 2017. Spatio-temporal travel characteristics of the elderly in an ageing society. Travel Behav. Soc. 9, 10-20. https://doi.org/10.1016/j.tbs.2017.07.005

The Swedish Transport Administration, 2019. Järnvägsnätsbeskrivning 2021 Bilaga 4 D Kapacitetsförutsättningar. Release 2019-09-27. 
Transport Analysis, 2011. Arbetspendling i storstadsregioner - en nulägesanalys. Rapport 2011:3.

van Wee, B., 2016. Accessible accessibility research challenges. J. Transp. Geogr. 51, 9-16. https://doi.org/10.1016/j.jtrangeo.2015.10.018

van Wee, B., 2012. How suitable is CBA for the ex-ante evaluation of transport projects and policies? A discussion from the perspective of ethics. Transp. Policy 19, 1-7. https://doi.org/10.1016/j.tranpol.2011.07.001

Vecchio, G., 2020. Microstories of everyday mobilities and opportunities in Bogotá: A tool for bringing capabilities into urban mobility planning. J. Transp. Geogr. 83, 102652. https://doi.org/10.1016/j.jtrangeo.2020.102652

Wismadi, A., Zuidgeest, M., Brussel, M., van Maarseveen, M., 2014. Spatial Preference Modelling for equitable infrastructure provision: An application of Sen's Capability Approach. J. Geogr. Syst. 16, 19-48. https://doi.org/10.1007/s10109-013-0185-4

Wong, R.C.P., Szeto, W.Y., Yang, L., Li, Y.C., Wong, S.C., 2018. Public transport policy measures for improving elderly mobility. Transp. Policy 63, 73-79. https://doi.org/10.1016/j.tranpol.2017.12.015

Ziegler, F., Schwanen, T., 2011. "I like to go out to be energised by different people": An exploratory analysis of mobility and wellbeing in later life. Ageing Soc. 31, 758-781. https://doi.org/10.1017/S0144686X10000498 